\title{
Evaluation and Analysis of Socio-Economic Development Level and Management in Guangxi Province of China
}

\author{
LI ZONGKENG ${ }^{1}$, LI ZHUORAN ${ }^{2}$, ANDRII MYKHAILOV ${ }^{3}$, WEI SHI $^{4}$, YANG ZHUQUAN ${ }^{5}$, \\ XIA SURONG ${ }^{6}$ \\ ${ }^{1}$ Department of Management, SUMY NATIONAL AGRARIAN UNIVERSITY, UKRAINE; HEZHOU UNIVERSITY, \\ GUANGXI, CHINA. E-mail: 463952482@qq.com \\ ${ }^{2}$ Department of Management, SUMY NATIONAL AGRARIAN UNIVERSITY, UKRAINE; XINXIANG UNIVERSITY, \\ HENAN, CHINA. E-mail: rainbow373@163.com \\ ${ }^{3}$ Department of Management, SUMY NATIONAL AGRARIAN UNIVERSITY, UKRAINE. \\ E-mail: andrii.mykhailov@snau.edu.ua \\ ${ }^{4}$ College of Education and Music, HEZHOU UNIVERSITY, GUANGXI, CHINA. E-mail: weishi666666@@163.com \\ ${ }^{5}$ School of Tourism, Physical and Health, HEZHOU UNIVERSITY, GUANGXI, CHINA. E-mail: 87232988@qq.com \\ ${ }^{6}$ Guangxi Zhuang Autonomous Region Tax Service, STATE TAXATION ADMINISTRATION, GUANGXI, CHINA. \\ E-mail: 306668051@qq.com
}

\begin{abstract}
This article takes 14 regions in Guangxi as the research object, selects ten indicators that can measure the level of socio-economic development, establishes an index system for evaluating the regional socio-economic development level of Guangxi regions. It uses the principal component analysis method and cluster analysis method to carry out comprehensive evaluation and difference analysis among the economic development level of Guangxi regions. First, the primary component analysis method comprehensively evaluates the economic development level of 14 regions in Guangxi. The results show that there are vast differences in the economic development levels of regions in Guangxi. Secondly, a systematic cluster analysis method uses to classify and analyze the differences between regions according to the similarity of economic development status. Finally, combined with the results of principal component analysis and cluster analysis, comprehensive evaluation analysis and discussion on the economic development status of various regions in Guangxi, and based on the evaluation results, proposed countermeasures for the socio-economic development and management Guangxi province of China.
\end{abstract}

Keywords: socio-economic development; management; principal component analysis; cluster analysis.

JEL Classifications: M21, O11, P52, R13, R58 


\section{Introduction.}

Over the past 40 years of reform and opening up, national economic development has gradually improved, and Guangxi is no exception. In recent years, the economic development level of Guangxi has grown year by year. Compared with the time before reform and opening-up, it has achieved rapid development. With the improvement of economic growth, the lives of people in Guangxi have also become more and more nourishing. The level of consumption has been significantly improved. However, in rapid economic development, the economic disparities in various regions of Guangxi are also expanding. The level of economic development among regions is very uneven, which seriously affects regional economic development in Guangxi. Suppose you want to change the status quo, narrow down the economic differences between regions in the province, and achieve the coordinated development of the regional economy. In that case, you must fully understand the financial situation in the region, combine the theory of regional economic differences, and formulate a reasonable development plan. Therefore, a comprehensive evaluation of the economic development level of regions in Guangxi is of great significance for realizing the coordinated and stable development of the provincial economy in the province.

Research on socio-economic development has been carried out at home and abroad. Haidai $\mathrm{O}$. (2019) indicates the main task of the government and scientific institutions is to create the organizational and economic conditions for the effective development of the agricultural sector based on common economic, social and environmental interests of society. Baboshkina, A., Savina, N. and Morozov, I. (2018) notes the basic condition of regional development is a public policy that will ensure sustainable socio-economic development of regions based on their potential and possible threats from the external environment. Mykhailov et al. (2020) indicate that land management is the primary mechanism of land policy implementation and the main link in land management and land use of any country. The analysis of the current implementation of the sustainable development model in the agricultural sector, conducted by Mykhailova L. et al. (2018), where the authors focus on combining the efforts of government bodies, socially responsible business, and the rural population and substantiate the need to improve the system of the functional environment, which should be based on the cluster development concept. Nosov A. et al. (2020) used cluster analysis of 15 post-Soviet countries; three groups were identified. During the last three periods, the ratio and content of the groups were the same, which indicates the stabilization of the cluster. Longfeng Wu and Seung Kyum Kim (2021) note that urban afforestation-related policies in China successfully promoted the equal distribution of green space. Regional analysis indicated divergent impacts of socio-economic development and government policies on green space equality. For example, Fu Haifeng (2014) used principal component analysis and cluster analysis to analyze and evaluate the economic development of 14 regions in Guangxi. Scholars such as Qi Zhaokun (2018) used the relevant data in recent years to conduct an empirical analysis of the economic development of Guangxi. Finally, they provided suggestions for the regional economic development of Guangxi according to the analysis results. Chen Chuan (2011) adopted a factor analysis method to evaluate the comprehensive strength of the economic development of various regions in Guangxi in 2010. Based on the evaluation results, put forward effective countermeasures to accelerate the growth of the commercial zone. Researchers such as Fu Yangli (2008) used factor analysis and cluster analysis methods to comprehensively evaluate the economic development level of 17 major regions in Shandong Province. According to relevant financial data, Zhang Zimin and others (2013) used the systematic clustering method and principal component analysis to analyze and evaluate the regional economic development of various regions in Guangxi.

This article takes 14 prefectures and regions in Guangxi as the research object, selects ten indicators that can measure the level of economic development, and establishes an index system for evaluating the regional economic development level of various regions in Guangxi. This paper uses principal component analysis and cluster analysis to comprehensively assess and differentiate the economic development level of different cities in Guangxi. First, this paper uses the primary 
component analysis method to comprehensively evaluate the socio-economic development level of 14 regions in Guangxi. The results show significant differences in the socio-economic development levels of regions in Guangxi; Secondly, a systematic cluster analysis method uses to classify and analyze the differences between cities according to the similarity of economic conditions. Finally, combined with the results of principal component analysis and cluster analysis, comprehensive evaluation analysis and discussion on the economic development status of various regions in Guangxi, and based on the evaluation results, proposed countermeasures for the socio-economic development of multiple regions.

\section{Selection of indicators and sources of data.}

The appropriate index system must establish a comprehensive and objective evaluation of the socio-economic development level of a region. Taking into account the overall situation of the economic development of Guangxi, based on referring to the relevant literature, the relevant variables that can reflect the socio-economic development of various regions in Guangxi selected as the analysis indicators:

x1--Regional GDP (100 million yuan);

x2--Regional GDP per capita (yuan);

x3--Per capita disposable income of urban residents (yuan);

$\mathrm{x} 4--$ Urban residents' living consumption expenditure (yuan);

x5--Total import and export of goods (RMB, 10,000 yuan);

x6--Actual foreign direct investment (ten thousand US dollars);

$x 7--T o t a l$ investment in fixed assets of the whole society (100 million yuan);

$x 8--T o t a l$ retail sales of consumer goods (100 million yuan);

x9--Total revenue and expenditure of public finance budget (100 million yuan);

$\times 10--T o t a l$ RMB deposits and loans of financial institutions (100 million yuan);

The data collected for analysis is mainly from "Guangxi Statistical Yearbook 2018", as shown in Table 1.

Table 1. Ten Economic Indicators of Regions in Guangxi

\begin{tabular}{|c|c|c|c|c|c|}
\hline Regions & $\boldsymbol{x}_{\mathbf{1}}$ & $\boldsymbol{x}_{\mathbf{2}}$ & $\boldsymbol{x}_{\mathbf{3}}$ & $\boldsymbol{x}_{\mathbf{4}}$ & $\boldsymbol{x}_{\mathbf{5}}$ \\
\hline Nanning & 4118.83 & 57948 & 332117 & 17279 & 6070866 \\
\hline Liuzhou & 2755.64 & 69249 & 32661 & 20909 & 1722399 \\
\hline Guilin & 2045.18 & 40632 & 32534 & 19005 & 700117 \\
\hline Wuzhou & 1338.1 & 44193 & 29359 & 19017 & 602406 \\
\hline Beihai & 1229.84 & 74378 & 31912 & 20238 & 2308381 \\
\hline Fangchenggang & 741.62 & 79351 & 32079 & 20538 & 7685445 \\
\hline Qinzhou & 1309.82 & 40160 & 31415 & 18392 & 3404673 \\
\hline Guigang & 1082.18 & 24857 & 28806 & 17791 & 238816 \\
\hline Yulin & 1699.54 & 29387 & 32159 & 18306 & 336580 \\
\hline Baise & 1361.76 & 37479 & 29126 & 17985 & 1884397 \\
\hline Hezhou & 548.83 & 26802 & 28899 & 16335 & 48443 \\
\hline Hechi & 734.6 & 20921 & 25647 & 16784 & 195498 \\
\hline Laibin & 663.69 & 30037 & 31047 & 18619 & 77312 \\
\hline Chongzuo & 907.62 & 43678 & 28813 & 17453 & 13388082 \\
\hline
\end{tabular}


Continued Table 1

\begin{tabular}{|c|c|c|c|c|c|}
\hline Regions & $\boldsymbol{x}_{\mathbf{6}}$ & $\boldsymbol{x}_{\mathbf{7}}$ & $\boldsymbol{x}_{\mathbf{8}}$ & $\boldsymbol{x}_{\mathbf{9}}$ & $\boldsymbol{x}_{\mathbf{1 0}}$ \\
\hline Nanning & 95753 & 4307.75 & 2204.16 & 978.46 & 19838 \\
\hline Liuzhou & 67893 & 2697.2 & 1155.64 & 554.35 & 6160.04 \\
\hline Guilin & 4179 & 2234.24 & 928.12 & 578.87 & 5410.95 \\
\hline Wuzhou & 1084.88 & 1330.15 & 445.87 & 326.85 & 1920.84 \\
\hline Beihai & 8445 & 1099.68 & 250.13 & 221.88 & 1593.3 \\
\hline Fangchenggang & 57159 & 672.77 & 124.02 & 168.07 & 1248.64 \\
\hline Qinzhou & 23187 & 1088.85 & 411.75 & 258.75 & 1637.67 \\
\hline Guigang & 3405 & 983.81 & 480.7 & 284.34 & 2076.79 \\
\hline Yulin & 3179 & 1689.33 & 728.86 & 457.17 & 3081.28 \\
\hline Baise & 7331 & 1226.41 & 277.35 & 459.02 & 2158.09 \\
\hline Hezhou & 667.35 & 722.02 & 178.85 & 210.88 & 1179.46 \\
\hline Hechi & 10.17 & 453.2 & 301.2 & 365.14 & 1786.88 \\
\hline Laibin & 1147 & 432.16 & 180.29 & 205.82 & 1169.6 \\
\hline Chongzuo & 370.23 & 970.5 & 146.09 & 255.62 & 1234.14 \\
\hline
\end{tabular}

From the above table, it can be preliminarily judged that the economic development level of Nanning and Liuzhou is at the forefront of Guangxi, while the economic development level of Hechi, Hezhou, and Chongzuo is at a low level in Guangxi.

\section{An empirical analysis of the economic development level of various regions in Guangxi principal component analysis.}

\subsection{Standardization of data.}

To standardize data, we adopt the method proposed by Yang Shanchao (2010) to our research. In order to eliminate the influence of different measurement units on the result analysis, with the help of SPSS components, this paper uses the $Z$ standardization method (that is, the difference between each variable value and its average value divided by the standard deviation of the variable) to perform dimensionless processing on the data in Table 1, and the results As shown in table 2.

Table 2. Standardized data

\begin{tabular}{|l|c|c|c|c|c|}
\hline \multicolumn{1}{|c|}{ Regions } & $\mathbf{x}_{\mathbf{1}}$ & $\mathbf{x}_{\mathbf{2}}$ & $\mathbf{x}_{\mathbf{3}}$ & $\mathbf{x}_{\mathbf{4}}$ & $\mathbf{x}_{\mathbf{5}}$ \\
\hline Nanning & 2.73726 & 0.72387 & 3.47333 & -0.8705 & 0.85908 \\
\hline Liuzhou & 1.33018 & 1.31973 & -0.2385 & 1.77146 & -0.2698 \\
\hline Guilin & 0.59685 & -0.1892 & -0.24 & 0.38569 & -0.5352 \\
\hline Wuzhou & -0.133 & -0.0014 & -0.2794 & 0.39443 & -0.5606 \\
\hline Beihai & -0.2447 & 1.59017 & -0.2477 & 1.28309 & -0.1177 \\
\hline Fangchenggang & -0.7487 & 1.85238 & -0.2457 & 1.50144 & 1.27823 \\
\hline Qinzhou & -0.1622 & -0.214 & -0.2539 & -0.0605 & 0.16693 \\
\hline Guigang & -0.3972 & -1.0209 & -0.2862 & -0.4979 & -0.6549 \\
\hline Yulin & 0.24008 & -0.7821 & -0.2447 & -0.1231 & -0.6296 \\
\hline Baise & -0.1086 & -0.3554 & -0.2823 & -0.3567 & -0.2277 \\
\hline Hezhou & -0.9477 & -0.9184 & -0.2851 & -1.5576 & -0.7044 \\
\hline Hechi & -0.7559 & -1.2285 & -0.3254 & -1.2308 & -0.6662 \\
\hline Laibin & -0.8291 & -0.7478 & -0.2585 & 0.10475 & -0.6969 \\
\hline Chongzuo & -0.5773 & -0.0286 & -0.2861 & -0.7439 & 2.75866 \\
\hline
\end{tabular}


Continued Table 2

\begin{tabular}{|l|c|c|c|c|c|}
\hline \multicolumn{1}{|c|}{ Regions } & $\mathbf{x}_{\mathbf{6}}$ & $\mathbf{x}_{\mathbf{7}}$ & $\mathbf{x}_{\mathbf{8}}$ & $\mathbf{x}_{\mathbf{9}}$ & $\mathbf{x}_{\mathbf{1 0}}$ \\
\hline Nanning & 2.4676 & 2.7503 & 2.91093 & 2.7576 & 3.29709 \\
\hline Liuzhou & 1.56535 & 1.21534 & 1.05673 & 0.8022 & 0.51864 \\
\hline Guilin & -0.4981 & 0.77411 & 0.65439 & 0.9152 & 0.36648 \\
\hline Wuzhou & -0.5983 & -0.0875 & -0.1984 & -0.247 & -0.3425 \\
\hline Beihai & -0.3599 & -0.3072 & -0.5446 & -0.731 & -0.409 \\
\hline Fangchenggang & 1.21772 & -0.7141 & -0.7676 & -0.979 & -0.479 \\
\hline Qinzhou & 0.11753 & -0.3175 & -0.2588 & -0.561 & -0.4 \\
\hline Guigang & -0.5231 & -0.4176 & -0.1368 & -0.443 & -0.3108 \\
\hline Yulin & -0.5304 & 0.25478 & 0.30202 & 0.3541 & -0.1068 \\
\hline Baise & -0.396 & -0.1864 & -0.4964 & 0.3626 & -0.2943 \\
\hline Hezhou & -0.6118 & -0.6671 & -0.6706 & -0.781 & -0.4931 \\
\hline Hechi & -0.6331 & -0.9233 & -0.4543 & -0.07 & -0.3697 \\
\hline Laibin & -0.5962 & -0.9434 & -0.6681 & -0.805 & -0.4951 \\
\hline Chongzuo & -0.6214 & -0.4303 & -0.7286 & -0.575 & -0.482 \\
\hline
\end{tabular}

The above table shows that the economic indicators of Nanning and Liuzhou are higher than the average level of Guangxi. The economic indicators of Hezhou, Hechi, Laibin, and Chongzuo are all lower than the intermediate level of Guangxi.

\subsection{KMO test and Bartlett test.}

To verify the applicability of principal component analysis, the correlation coefficient matrix between variables and KMO test and Bartlett's test statistics calculated with the help of SPSS software. The results are shown in Table 3 and Table 4 below.

Table 3. Correlation Coefficient Matrix

\begin{tabular}{|c|c|c|c|c|c|c|c|c|c|c|}
\hline & $\mathrm{x}_{1}$ & $\mathrm{x}_{2}$ & $\mathrm{x}_{3}$ & $\mathrm{x}_{4}$ & $\mathrm{x}_{5}$ & $\mathrm{x}_{6}$ & $\mathrm{x}_{7}$ & $\mathrm{x}_{8}$ & $\mathrm{x}_{9}$ & $\mathrm{x}_{10}$ \\
\hline $\mathrm{x}_{1}$ & 1.000 & 0.352 & 0.796 & 0.129 & 0.083 & 0.755 & 0.991 & 0.975 & 0.939 & 0.928 \\
\hline $\mathrm{x}_{2}$ & 0.352 & 1.000 & 0.223 & 0.776 & 0.436 & 0.654 & 0.343 & 0.225 & 0.115 & 0.257 \\
\hline $\mathrm{x}_{3}$ & 0.796 & 0.223 & 1.000 & -0.232 & 0.248 & 0.719 & 0.800 & 0.844 & 0.797 & 0.952 \\
\hline $\mathrm{x}_{4}$ & 0.129 & 0.776 & -0.232 & 1.000 & 0.029 & 0.320 & 0.094 & -0.003 & -0.108 & -0.105 \\
\hline $\mathrm{x}_{5}$ & 0.083 & 0.436 & 0.248 & 0.029 & 1.000 & 0.326 & 0.112 & 0.020 & 0.008 & 0.154 \\
\hline $\mathrm{x}_{6}$ & 0.755 & 0.654 & 0.719 & 0.320 & 0.326 & 1.000 & 0.734 & 0.732 & 0.617 & 0.766 \\
\hline $\mathrm{x}_{7}$ & 0.991 & 0.343 & 0.800 & 0.094 & 0.112 & 0.734 & 1.000 & 0.973 & 0.938 & 0.931 \\
\hline $\mathrm{x}_{8}$ & 0.975 & 0.225 & 0.844 & -0.003 & 0.020 & 0.732 & 0.973 & 1.000 & 0.947 & 0.960 \\
\hline $\mathrm{x}_{9}$ & 0.939 & 0.115 & 0.797 & -0.108 & 0.008 & 0.617 & 0.938 & 0.947 & 1.000 & 0.923 \\
\hline $\mathrm{x}_{10}$ & 0.928 & 0.257 & 0.952 & -0.105 & 0.154 & 0.766 & 0.931 & 0.960 & 0.923 & 1.000 \\
\hline
\end{tabular}

It can be seen from Table 3 that there is a strong correlation between variables. It can be seen from Table 4 that the observed value of Bartlett's sphericity test statistic is $202.475, \mathrm{P}$-value $<0.05$, and KMO measurement value is 0.699 . Therefore, the principal component analysis method can be used to study the regional socio-economic development of Guangxi. 
Table 4. KMO Test and Bartlett Test

\begin{tabular}{|c|c|c|}
\hline \multicolumn{2}{|c|}{ Kaiser-Meyer-Olkin metric with sufficient sampling } & 0.699 \\
\hline \multirow{3}{*}{ Bartlett's sphericity test } & Approximate chi-square & 202.475 \\
\cline { 2 - 3 } & Df & 45 \\
\cline { 2 - 3 } & Sig. & 0.000 \\
\hline
\end{tabular}

\subsection{Extraction of principal components.}

In order to determine the principal component, the SPSS software used to find the correlation coefficient matrix eigenvalues, the primary component contribution rate and the cumulative contribution rate. The results show in the following table 5.

Table 5. Eigenvalue and variance contribution rate and cumulative variance phase contribution rate

\begin{tabular}{|c|c|c|c|c|c|c|}
\hline \multirow{2}{*}{ Ingredient } & \multicolumn{3}{|c|}{ Initial eigenvalue } & \multicolumn{2}{c|}{ Extract the sum of squared loads } \\
\cline { 2 - 7 } & $\begin{array}{c}\text { Characteristic } \\
\text { root }\end{array}$ & $\begin{array}{c}\text { Percentage of } \\
\text { total feature } \\
\text { value }\end{array}$ & $\begin{array}{c}\text { Cumulative } \\
\text { contribution } \\
\text { rate }\end{array}$ & $\begin{array}{c}\text { Characteristic } \\
\text { root }\end{array}$ & $\begin{array}{c}\text { Percentage of } \\
\text { total feature } \\
\text { value }\end{array}$ & $\begin{array}{c}\text { Cumulative } \\
\text { contribution } \\
\text { rate }\end{array}$ \\
\hline 1 & 6.330 & 63.304 & 63.304 & 6.330 & 63.304 & 63.304 \\
\hline 2 & 2.043 & 20.430 & 83.734 & 2.043 & 20.430 & 83.734 \\
\hline 3 & 1.070 & 10.698 & 94.433 & 1.070 & 10.698 & 94.433 \\
\hline 4 & 0.310 & 3.098 & 97.530 & & & \\
\hline 5 & 0.131 & 1.309 & 98.840 & & & \\
\hline 6 & 0.056 & 0.559 & 99.399 & & & \\
\hline 7 & 0.043 & 0.426 & 99.825 & & & \\
\hline 8 & 0.011 & 0.113 & 99.938 & & & \\
\hline 9 & 0.005 & 0.047 & 99.984 & & & \\
\hline 10 & 0.002 & 0.016 & 100.000 & & & \\
\hline
\end{tabular}

From Table 5 above, the characteristic values of the first three variables are $6.330,2.043$, and 1.070. All three eigenvalues are more significant than 1 . According to the selection principle, the characteristic root is greater than or equal to 1 , selecting the first three principal components. Besides, their cumulative variance contribution rate reached $94.433 \%$. It shows that these three main components can represent most of the original variables' information and are sufficiently confident to reflect the comprehensive level of regional economic development. It can also be seen intuitively from the gravel diagram that the image decreases monotonically at component 1 , component 2 , and component 3 , and the inflection point is at the third component. From component 4, the image tends to be stable, and the amount of information it contains is low. Therefore, we select the first three components as the principal components.

\subsection{Principal component load.}

The SPSS software is used to find the principal component load matrix after rotation to establish the primary component analysis model, calculate each region's overall score, and comprehensively evaluate it. The results are shown in Table 6 below. 
Table 6. Principal component load matrix after rotation

\begin{tabular}{|c|c|c|c|}
\hline \multirow{2}{*}{ Variables } & \multicolumn{3}{|c|}{ Ingredient } \\
\cline { 2 - 4 } & $\mathbf{1}$ & $\mathbf{2}$ & $\mathbf{3}$ \\
\hline $\mathrm{x}_{1}$ & 0.965 & 0.198 & -0.007 \\
\hline $\mathrm{x}_{2}$ & 0.201 & 0.878 & 0.376 \\
\hline $\mathrm{x}_{3}$ & 0.891 & -0.121 & 0.305 \\
\hline $\mathrm{x}_{4}$ & -0.079 & 0.976 & -0.109 \\
\hline $\mathrm{x}_{5}$ & 0.034 & 0.112 & 0.962 \\
\hline $\mathrm{x}_{6}$ & 0.730 & 0.457 & 0.323 \\
\hline $\mathrm{x}_{7}$ & 0.964 & 0.168 & 0.022 \\
\hline $\mathrm{x}_{8}$ & 0.989 & 0.064 & -0.038 \\
\hline $\mathrm{x}_{9}$ & 0.964 & -0.053 & -0.063 \\
\hline $\mathrm{x}_{10}$ & 0.981 & -0.009 & 0.148 \\
\hline
\end{tabular}

As can be seen from Table 6, the first principal component mainly describes regional GDP, per capita disposable income of urban residents, total social fixed asset investment, total retail sales of social consumer goods, total public budget revenue and expenditure and RMB deposits of financial institutions information on total loans. The first principal component is also an essential factor that reflects the comprehensive strength of each city's economic growth. Therefore, the first principal component is defined as the economic power factor and expressed in terms of F1. The second principal component has a higher load on regional GDP per capitax2 and urban residents' living consumption expenditurex4, which mainly reflects the living standard of urban people and can be defined as the living standard factor, expressed by F3.

Combined with Table 6, use SPSS software to find the linear coefficient of the principal component analysis model, as shown in Table 7 below.

Table 7. Principal Component Score Coefficient Matrix

\begin{tabular}{|c|c|c|c|}
\hline \multirow{2}{*}{ Variables } & \multicolumn{3}{|c|}{ Ingredient } \\
\cline { 2 - 4 } & $\mathrm{F}_{1}$ & $\mathrm{~F}_{2}$ & $\mathrm{~F}_{3}$ \\
\hline $\mathrm{x}_{1}$ & 0.163 & 0.067 & -0.114 \\
\hline $\mathrm{x}_{2}$ & -0.031 & 0.406 & 0.167 \\
\hline $\mathrm{x}_{3}$ & 0.139 & -0.153 & 0.213 \\
\hline $\mathrm{x}_{4}$ & -0.047 & 0.549 & -0.246 \\
\hline$x_{5}$ & -0.074 & -0.096 & 0.810 \\
\hline $\mathrm{x}_{6}$ & 0.085 & 0.164 & 0.147 \\
\hline $\mathrm{x}_{7}$ & 0.162 & 0.046 & -0.084 \\
\hline $\mathrm{x}_{8}$ & 0.176 & -0.001 & -0.121 \\
\hline $\mathrm{x}_{9}$ & 0.178 & -0.060 & -0.122 \\
\hline $\mathrm{x}_{10}$ & 0.163 & -0.071 & 0.052 \\
\hline
\end{tabular}

According to the principal component score coefficient matrix of Table7, three linear combinations of principal components are obtained as follows: 


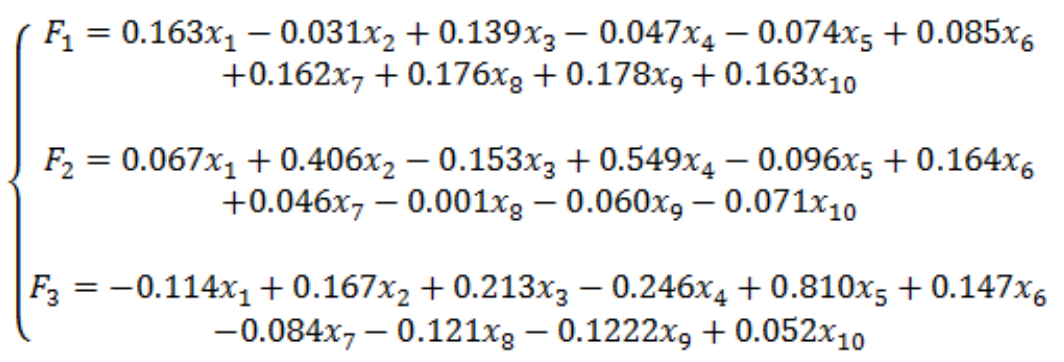

\subsection{Principal component score and comprehensive score.}

From the eigenvalue and contribution rate information in Table 5, the principal component comprehensive score model can be established as below:

$$
F=\left(0.63304 F_{1}+0.20430 F_{2}+0.10698 F_{3}\right) / 0.94433
$$

Substitute the data in Table 2 into the model (1) to calculate the principal component score of each sample, and then use model (2) to calculate the comprehensive score of each sample. The results are shown in Table 8.

Table 8. Principal component score and a comprehensive score of each region

\begin{tabular}{|c|c|c|c|c|c|}
\hline Regions & $\mathrm{F}_{1}$ & $\mathrm{~F}_{2}$ & $\mathrm{~F}_{3}$ & Overall ratings $(\mathrm{F})$ & Total ranking \\
\hline Nanning & 3.0792 & -0.48263 & 1.07107 & 1.965239 & 1 \\
\hline Liuzhou & 0.82234 & 1.88781 & -0.70725 & 0.830592 & 2 \\
\hline Guilin & 0.51284 & 0.13618 & -0.98964 & 0.246598 & 3 \\
\hline Wuzhou & -0.23683 & 0.24081 & -0.63988 & -0.16918 & 7 \\
\hline Beihai & -0.54854 & 1.38306 & -0.06353 & -0.07149 & 6 \\
\hline Fangchenggang & -0.78009 & 1.70082 & 1.43554 & 0.007223 & 4 \\
\hline Qinzhou & -0.31677 & -0.04163 & 0.20186 & -0.18744 & 8 \\
\hline Guigang & -0.26618 & -0.66448 & -0.5814 & -0.36645 & 11 \\
\hline Yulin & 0.17747 & -0.36015 & -0.87454 & -0.05479 & 5 \\
\hline Baise & -0.14641 & -0.35629 & -0.24553 & -0.19174 & 14 \\
\hline Hezhou & -0.53746 & -1.22981 & -0.17612 & -0.61033 & 13 \\
\hline Hechi & -0.37867 & -1.22766 & -0.39573 & -0.53286 & 10 \\
\hline Laibin & -0.64592 & -0.25281 & -0.53015 & -0.51726 & -0.34812 \\
\hline Chongzuo & -0.73497 & -0.73323 & 2.49528 & & 5 \\
\hline
\end{tabular}

The first principal component reflects the overall strength of socio-economic development. The second primary component reflects the overall status of residents' living standards. The third principal component reflects the foreign economic and trade situation. It can be seen from the three columns of main component scores and comprehensive scores and rankings in Table 8 that the comprehensive rankings of the three regions of Nanning, Liuzhou, and Guilin are among the best. Among them, Nanning, as the capital of Guangxi, ranking first, with a comprehensive score of 1.965239, more than twice the comprehensive score of Liuzhou, which ranked second and far 
exceeded other regions, indicating that Nanning has the highest level of economic development. The regions with lower comprehensive scores are Hezhou, Hechi, Laibin and other regions. Their economic development level is relatively small, and their economic development lags. Judging from the scores of the three principal components, the scores of the first principal components in Nanning, Liuzhou, and Guilin are all greater than zero, indicating that these three regions have more strong comprehensive strength in economic development and a better level of economic growth. Liuzhou, Fangchenggang and Beihai have higher scores for the second principal component, indicating that the living standards of these three regions are higher.

Chongzuo, Fangchenggang, Guigang, Laibin, Guilin, and Nanning scored higher on the third principal component, indicating that these regions mainly rely on foreign trade to drive economic growth.

\section{An empirical analysis of the economic development of Guangxi regions-cluster analysis.}

To more accurately analyze the economic development of cities in Guangxi, find out the similarities and differences of economic growth in various regions, and put forward corresponding countermeasures, this paper uses SPSS to systematically analyze the 14 prefecture-level regions in Guangxi to obtain clusters.

It can be seen from Figure 1 that these cities can be divided into five categories according to the similarity of the economic development status of various regions. The results are as follows:

Category 1: 1-Nanning;

Category 2: 2-Liuzhou;

Category 3: 3-Guilin; 4-Wuzhou; 7-Qinzhou; 8-Guigang; 9-Yulin; 10-Baise; 11-Hezhou; 12-Hechi; 13-guest;

Category 4: 5-Beihai; 6-Fangchenggang;

Category 5: 14-Chongzuo.

Nanning is the capital of Guangxi. It has a good economic foundation, strong development strength, small area, dense population, developed tertiary industry, high overall population quality, strong competitiveness, and comprehensive economic power is much higher than 13 other regions. Therefore, it has become a category.

The picture is shown in Figure 1.

Nanning is the capital of Guangxi. First, it has an excellent economic foundation and strong development strength. Second, the area is small, and the population is dense. Third, the tertiary industry is relatively developed. The overall quality of the population is high; fourth, the competitiveness is strong, and the comprehensive economic strength is more top in 13 other regions. That's why it can be listed separately as a category.

The geographical locations of Guilin, Wuzhou, Qinzhou, Guigang, Yulin, Baise, Hezhou, and Hechi are relatively disparate, and the natural environment are also unique. Therefore, they are generally low in regional GDP, fiscal revenue, and consumption levels. Although the government has given certain policies and financial support to these areas, their infrastructure construction is still lagging, teaching and education levels are low, teachers are not strong enough, technology development is backward, population quality is not high, and social security is relatively weak, so these regions are grouped.

Beihai and Fangchenggang are both port regions with similar geographical locations and are close to the seaside. Both cities are small and have a large per capita living area. The industrial value of the industry is also similar, and the development direction has the same trend. Therefore, they are classified into the same category.

Although Chongzuo is a resource-gathering area in western Guangxi, its economic foundation is still weak, and public infrastructure is not perfect. Human resources cannot be used to the maximum 
benefit. When there is a lack of professional and technical personnel, it cannot be replenished in time, so it is classified as a relatively backward economic development category.

Figure 1. Clustering map of socio-economic development levels of various regions in Guangxi

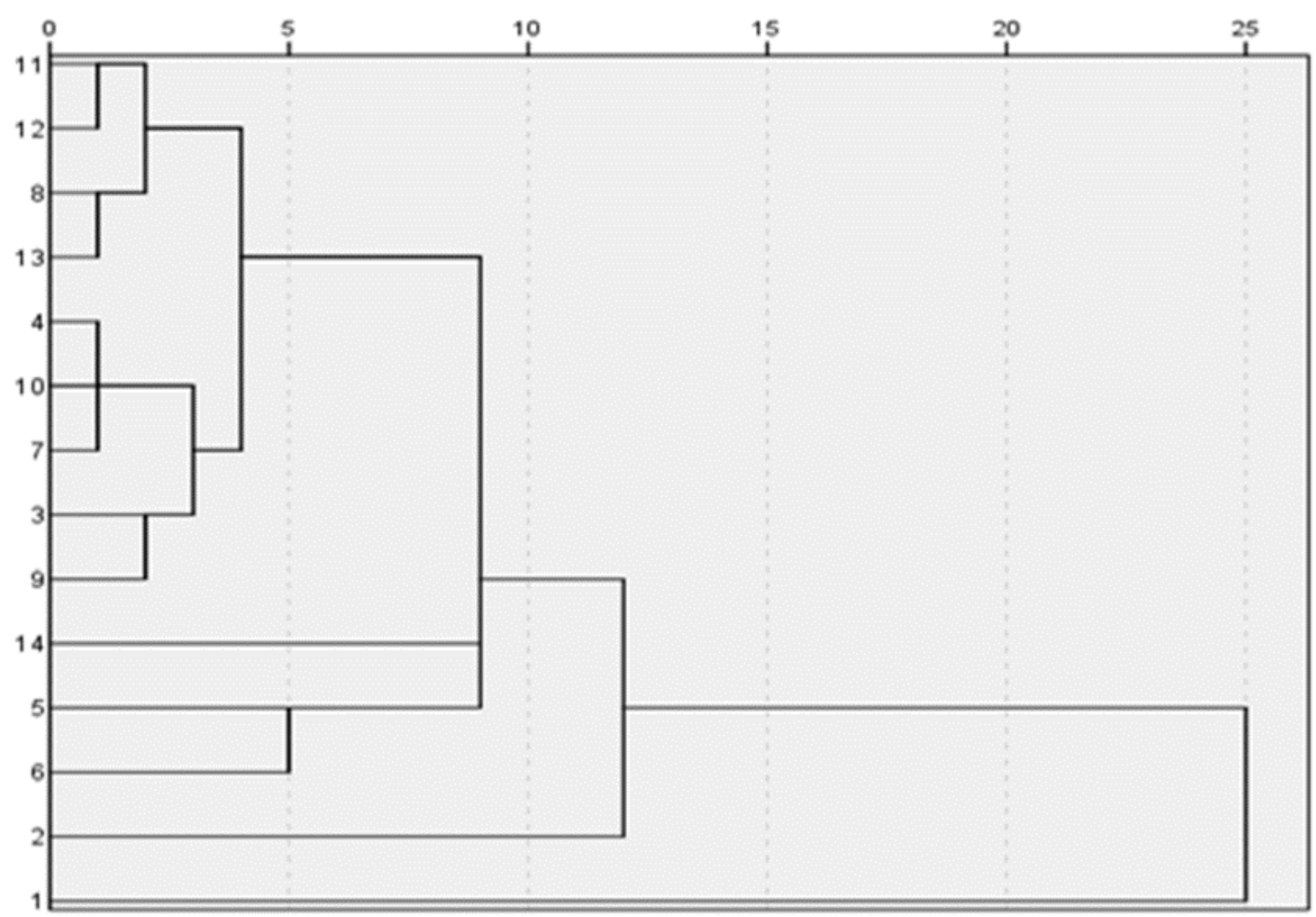

Where: 1-Nanning, 2-Liuzhou, 3-Guilin, 4-Wuzhou, 5-Beihai, 6-Fangcheng, 7-Qinzhou, 8-Guigang, 9-Yulin, 10-Baise, 11Hezhou, 12-Hechi, 13-Laibing, 14-Chongzuo.

\section{Conclusions and recommendations.}

Combine the results of principal component analysis and cluster analysis, and it can be seen that there are certain differences in the socio-economic development levels among the 14 regions in Guangxi province, mainly due to factors such as the industrial structure, economic foundation, geographical conditions and location differences of various regions. As a provincial capital region, Nanning has an excellent economic foundation and strong development strength. It has an absolute advantage in terms of economic aggregate. As the most important industrial region in Guangxi, Liuzhou has a more developed secondary industry, and its economic aggregate is also higher among regions in Guangxi. As a famous tourist region in the country, Guilin has unique tourism resources. The tourism industry and other service industries are relatively developed. The development of its tourism industry has driven the overall growth of Guilin's economy. The two regions of Fangchenggang and Beihai, although their economic aggregates are relatively low compared to the other areas, they have higher per capita incomes. Chongzuo, Guigang, Baise, Laibin, Hechi, and Hezhou have always been relatively backward economic development regions in Guangxi. These regions are located in remote areas, with inconvenient transportation, a relatively weak economic foundation, and low education. In light of the above results, some suggestions for narrowing the regional socio-economic gap in Guangxi are proposed: 


\subsection{Promote the upgrading of Nanning's industrial structure and promote the development of Nanning's tertiary industry.}

As the capital of Guangxi, Nanning City has an excellent economic foundation, developed tertiary industry, and a large amount of social fixed investment. The high-tech industrial zone has more professionals, and the overall quality of the population is generally higher. More and more small and medium-sized enterprises invest in construction, creating many job opportunities for people, and residents' income is relatively stable. Therefore, the comprehensive economic strength of Nanning ranks first in Guangxi. The China-ASEAN Expo is permanently located in Nanning, which brings opportunities for the economic development of the Chamber of Commerce in Nanning. Therefore, Nanning should continue to tap its strengths, give full play to the advantages of its service industry, integrate the economy of the Chamber of Commerce with overseas contacts, and accelerate the development and cooperation with ASEAN. At the same time, Nanning should continue to innovate and develop the economy to attract people at home and abroad to invest here, expand Nanning's economic market, and strive to build Nanning into a regional international city.

\subsection{Build a circular economy system in Liuzhou industrial region.}

Liuzhou is known as an industrial town in western China and is a famous industrial region in Guangxi. In reform and opening up, Liuzhou has continuously tapped its advantages to find suitable economic development principles. In recent years, Liuzhou's economic development has achieved remarkable results, mainly due to the rapid growth of the secondary industry. The gradual development and steady improvement of the industry is an essential guarantee for Liuzhou to rank among the top in Guangxi's economic ranking of regions. However, after years of economic development, Liuzhou, like an old industrial base, the GDP has increased significantly, the environmental pollution problem has become increasingly severe. Environmental pollution cannot be underestimated, which directly affects the normal growth and development of animals and plants, and even threatens human health. Therefore, while ensuring the sustained and rapid economic development of Liuzhou, we must protect the environment, promote the development of a circular economy, formulate measures for environmental protection, strictly approve projects, set limits for the total amount of pollutant emission control and go green road to development.

\subsection{Accelerate the process of industrialization and industrialization of a tourist region.}

Guilin has the finest mountains and waters under heaven, and Guilin is the most famous tourist region in Guangxi. It has a particular reputation both domestically and internationally, and tourism has become the pillar industry of Guilin. For a long time, Guilin has always adhered to the development strategy of "taking agriculture as the foundation and taking tourism as the leader". This measure has extensively promoted the economic development of Guilin and has made Guilin's economic development gradually increase. However, due to the simplification of its industrial structure and the low speed of industrial development, the economic development of Guilin has been limited to a certain extent. Therefore, Guilin should take tourism as the pillar industry, accelerate the industrialization and industrialization of the tourist region, and at the same time adjust the single industrial structure, promote the diversification of industrial economic development, and build Guilin as export-oriented industrial commerce and tourism region.

\subsection{Develop the port economy in coastal areas and enhance the leading role of the foreign economy.}

Fangchenggang, Qinzhou, and Beihai are the three most significant port regions in the Beibu Gulf of Guangxi. Due to their unique location advantages, in recent years, the three regions of Qinzhou, Beihai and Fangchenggang have relied on their unique location advantages to develop the port economy. The level of development is getting higher and higher. Although these three regions are port regions located along the coast, the infrastructure of these three essential ports is not complete. 
Most of them are repeated construction, there is no practicality, and the functional positioning is not clear, resulting in the economic development of these three major port regions. Unbalanced to a certain extent. In this regard, Fangcheng Port, Qinzhou, and Beihai should pay attention to related projects of infrastructure construction, solicit suggestions from citizens, promote public infrastructure construction, and seize multiple strategic opportunities, strive to win national support, improve the efficiency of port operations, and stimulate economic growth. At the same time, it is also necessary to formulate development plans for the three regions of the port, clarify the advantages of each port, position the function, develop the port economy, and accelerate the implementation of the integration process of Fangcheng Port, Qinzhou and Beihai.

\subsection{Improve infrastructure construction in backward areas and promote the economic development of local characteristics.}

Hechi, Baise, and Chongzuo are located in remote areas, with special topography, poor transportation, low education, and inadequate infrastructure. Moreover, industrial development is relatively backward, and economic growth is mainly driven by agriculture. Therefore, the speed of economic development is slow, and the overall level of economic development is low. Also, whether it is in regional industrialization and urbanization or in terms of increasing residents' income and improving people's living standards, there is still room for improvement. Therefore, the municipal government departments should take corresponding measures to improve infrastructure construction, promote the optimization of industrial structure, encourage and guide each city to give full play to its regional resource advantages, develop a special regional economy, promote economic growth, accelerate the urban-rural integration process, and improve people's living standards.

\section{References}

1. Baboshkina, A., Savina, N., Morozov, I. (2018), Management Processes in the Development of the Socio Economic Environment of the Region. Journal of advanced research in law and economics, ASERS Publishing, vol. 9(2), pages 376-385. Available:

https://ideas.repec.org/a/srs/jarle0/v9y2018i2p376-385.html

2. Chen, CHUAN. (2011), Evaluation and analysis of comprehensive strength of urban economic development in Guangxi in 2010-- Based on the results of factor analysis [J]. Modern Economic Information, (21), 309-312.

3. Fu, HAIFENG and Wei, HAIMING. (2014), Analysis and Evaluation of Guangxi City Economic Development Level Based on Principal Component Analysis and Cluster Analysis [J]. Economic Forum, 2014 (07), 65-70.

4. Fu, YANGLI and Wu, QUNYING. (2008), Comprehensive evaluation of economic development level of major cities in Shandong Province based on factor analysis and cluster analysis [J]. Scientific and technological information, (34), 373-374.

5. Guangxi Statistical Yearbook. (2018), [Online]. [2019.08.] Available: https://www.yearbookchina.com/navibooklist-n3018101902-1.html

6. Haidai, O. (2019) Socio - Economic Direction of Agricultural Sector Development in Ukraine, Proceedings of the 33rd IBIMA Conference: 10-11 April 2019, Granada, Spain. Available: https://ibima.org/accepted-paper/socio-economic-direction-of-agricultural-sector-developmentin-ukraine/

7. Longfeng, WU and Seung, Kyum, KIM. (2021), Does socio-economic development lead to more equal distribution of green space? Evidence from Chinese cities, Science of The Total Environment, Volume 757, 143780, ISSN 0048-9697, https://doi.org/10.1016/j.scitotenv.2020.143780. Available: https://www.sciencedirect.com/science/article/pii/S0048969720373113

8. MYKHAILOV, A., MAKAROVA, V., KAPINOS, N., PETROVA, N. (2020) Land management's development in the period of land relations reform in Ukraine. Estudios de Economía Aplicada. Vol 38, No 4 (2020) Available: http://ojs.ual.es/ojs/index.php/eea/article/view/3963 DOI: 
http://dx.doi.org/10.25115/eea.v38i4.3963

9. Mykhailova, L., Stoyanets, N., Mykhailov, A., Kharchenko, T. \& Hrabrin, Bachev (2018). Sustainable development of the Ukrainian agrarian sector: perspectives and challenges. Problems and Perspectives in Management, 16(3), pp. 28-39. DOI:10.21511/ppm.16(3).2018.03

10.Nosov, S., Tcypin, A., Halasova, S., Zveryaeva, S., Shel, T., Artemova, E. (2020) Classification of Post-Soviet Countries by the Level of Socio-Economic Development. Proceedings of the 35th IBIMA Conference: 1-2 April 2020, Seville, Spain. Available:

https://ibima.org/accepted-paper/classification-of-post-soviet-countries-by-the-level-of-socioeconomic-development/

11.Qi, Zhaokun. (2018), A Study on the Differences in Economic Development in Guangxi Regions [J]. Qinzhou University News, 33(01), 35-41.

12.Yang, SHANCHAO. (2010), Basic application of SPSS statistical software [M]. Guangxi University Press, 23-28

13.Zhang, ZIMIN, Fan, YANYING, Chen, GUANPING and Li, JIANJI. (2013), Research on the difference of regional economic development in Guangxi based on factor and cluster analysis [J]. Science and Technology and Industry, 13(02), 15-43. 